\title{
BMJ Open Features of alcohol harm reduction advertisements that most motivate reduced drinking among adults: an advertisement response study
}

\author{
Melanie A Wakefield, ${ }^{1}$ Emily Brennan, ${ }^{1}$ Kimberley Dunstone, ${ }^{1}$ Sarah J Durkin, ${ }^{1}$ \\ Helen G Dixon, ${ }^{1}$ Simone Pettigrew, ${ }^{2}$ Michael D Slater ${ }^{3}$
}

To cite: Wakefield MA, Brennan $\mathrm{E}$, Dunstone $\mathrm{K}$, et al. Features of alcohol harm reduction advertisements that most motivate reduced drinking among adults: an advertisement response study. BMJ Open 2017;7: e014193. doi:10.1136/ bmjopen-2016-014193

- Prepublication history and additional material is available. To view please visit the journal (http://dx.doi.org/ 10.1136/bmjopen-2016014193).

Received 7 September 2016 Revised 27 January 2017 Accepted 6 February 2017

CrossMark

\section{${ }^{1}$ Centre for Behavioural Research in Cancer, Cancer Council Victoria, Melbourne, Victoria, Australia \\ ${ }^{2}$ School of Psychology and Speech Pathology, Curtin University, Bentley, Western Australia, Australia \\ ${ }^{3}$ School of Communication, Ohio State University, Columbus, Ohio, USA}

\section{Correspondence to}

Professor Melanie Wakefield; melanie.wakefield@cancervic. org.au

\section{ABSTRACT}

Objectives: To improve the effectiveness of alcohol harm reduction mass media campaigns, this study aimed to (1) identify existing advertisements (ads) with greatest potential to motivate reduced alcohol consumption, (2) assess consistency across audience subgroups in ad effectiveness and (3) identify ad features associated with effectiveness.

Design: Cross-sectional online ad response study with random assignment to view ads.

Participants: 2174 Australian adult weekly drinkers recruited from an online panel.

Procedure: Participants were randomly assigned to view three of 83 English-language alcohol harm reduction ads. Each ad was viewed and rated by a mean of 79 participants.

Outcome measure: After viewing each ad, participants reported the extent to which they felt motivated to reduce their drinking. Ads were ranked from most to least motivating using predicted means adjusted for demographic characteristics and alcohol consumption. We compared the characteristics of the top-ranked $15 \%$ of ads (most motivating) with the middle $70 \%$ and bottom $15 \%$.

Results: An ad about the link between alcohol and cancer ('Spread') was most motivating, whereas an ad that encouraged drinking water instead of beer ('Add nothing') was least motivating. Top-ranked ads were more likely than other ads to feature a 'why change' message and less likely to carry a 'how to change' message; more likely to address long-term harms; more likely to be aimed at the general adult drinking population and more likely to include drinking guidelines. There was substantial overlap in top-ranked ads for younger versus older adults, men versus women and high-risk versus low-risk drinker subgroups.

Conclusions: The effectiveness of alcohol harm reduction campaigns may be improved by directly communicating alcohol's long-term harms to the general adult population of drinkers along with drinking guidelines. By doing so, campaigns can also efficiently influence high-risk drinkers and key demographic subgroups.

\section{Strengths and limitations of this study}

- A large and diverse set of existing alcohol harm reduction advertisements was ranked according to each advertisement's ability to motivate reduced alcohol consumption.

- Motivation responses were provided by a large sample of adult weekly drinkers with similar demographic and alcohol consumption characteristics to those observed in a national benchmark sample.

- All ads were presented in a standard way with consistent exposure, although such exposure may not reflect how viewers might respond in a natural media viewing situation.

- The motivation outcome used is a perceived effectiveness outcome that predicts smoking behaviour change among smokers after exposure to tobacco control ads.

- Further research is required to validate the motivation measure as a predictor of subsequent reduced alcohol consumption.

\section{BACKGROUND}

Alcohol use ranks among the top five risk factors for global disease burden, accounting for $5.5 \%$ of all disability adjusted life years lost. ${ }^{1}$ About $70 \%$ of this alcohol burden is due to long-term harms such as cancer, cardiovascular disease, neuropsychiatric disorders and infectious disease, with the remainder due to short-term harms including unintentional and intentional injury. ${ }^{2}$ In developed nations such as Australia, the UK, Ireland and the USA, population awareness of the range of harms from alcohol is limited. ${ }^{3-8}$ For example, an Australian survey in 2014 found prompted awareness of the link between alcohol use and serious conditions to vary substantially, ranging from $80 \%$ for cirrhosis of the liver to only $15 \%$ for breast cancer. ${ }^{9}$ Population surveys also show poor 
awareness of the levels of alcohol consumption associated with harm $^{10}$ and low-risk drinking guidelines. ${ }^{9}{ }^{11}$ Together, these findings indicate considerable scope for public education to improve awareness and understanding of alcohol-associated harms, with the broader goal of contributing to reductions in risky drinking. A keener awareness of harms is also critical if strong public support is to be expected for alcohol policy reform. ${ }^{12}$

One means for achieving improved awareness could be through the delivery of mass media campaigns that warn the public of the negative consequences of alcohol use. Mass media campaigns have been successful for changing many health behaviours, ${ }^{13}$ most notably in reducing tobacco use. ${ }^{14} 15$ Yet aside from the success of campaigns to reduce drink driving ${ }^{16}$ there is limited evidence to date that alcohol harm reduction campaigns-most of which have focussed on youth-are effective. ${ }^{13} 1718$ This limited success could be due to many factors, ${ }^{13}$ including inadequate reach, frequency and duration, the lack of integration of public education with a sustained comprehensive approach involving other alcohol control policies including price controls ${ }^{17} 19$ and the unrestricted volume of pro-drinking alcohol marketing which dwarfs sporadic educational efforts. ${ }^{19}{ }^{20}$ Integration of policy and public education efforts is typified in the successful whole-ofpopulation approach in tobacco control that has changed social norms and reduced adult and youth smoking rates. ${ }^{13} 1521-26$ Evidence from tobacco control has also demonstrated that message attributes are more important than audience attributes in identifying effective campaigns, ${ }^{14} 27$ with particular campaign messagessuch as those promoting why people need to quit rather than how to quit and those that evoke negative emotion through graphic imagery or personal stories of serious harm-performing well across many population subgroups. ${ }^{14} 27-32$

Several recent successful examples of alcohol harm reduction advertising also suggest that a general population, rather than targeted audience, approach may hold promise. ${ }^{33} 34$ Conceptualised more generally, mass media campaigns can either target messages to particular subgroups (typically high-risk individuals or key demographic groups) or use a whole-of-population approach. While targeting campaigns to subgroups holds logical appeal, others have noted that this approach also carries risks. A focus on particular highrisk population subgroups (such as young adults) can exempt people outside those groups (such as older adults) from heeding the message even though they may also be at risk, promoting a culture in which 'our' drinking is acceptable and 'their' drinking is problematic. ${ }^{35}$ Relatedly, campaigns that are narrowly targeted miss the opportunity to change broader social norms by encouraging the wider population to reflect on their own behaviour and generating wider public debate that can build support for policy change. ${ }^{36}$ Finally, narrowly targeted campaigns can be inefficient, requiring multiple messages for different groups which are expensive to develop and sustain. ${ }^{36}$ As Hornik and colleagues have suggested, there may be merit in adopting a 'common denominator' approach, ${ }^{36}{ }^{38}$ where a single campaign is used to address beliefs that are commonly shared across many subgroups, thus serving multiple audiences at the same time. Such an approach also provides the opportunity to stimulate broader community discussion and normative change.

Given limited resources, it is crucial that funding is devoted to messages with the greatest likelihood of promoting behaviour change. Perceived effectiveness measures are often used to pretest the likely success of potential campaign messages, with several studies on tobacco control messages establishing their predictive validity for increased intentions to quit, ${ }^{39}$ more thoughts about quitting ${ }^{40}$ and behaviour change. ${ }^{41}{ }^{42} \mathrm{~A}$ recent review defined perceived effectiveness as "the extent to which a message recipient believes that a health message will affect him or her personally in terms of the particular message objectives". ${ }^{43}$ As a step towards identifying specific advertisements (ads) and message features that may hold the most promise for population-wide behaviour change, the primary aim of the study was to examine the comparative perceived effectiveness of a large pool of alcohol harm reduction ads with variable features, using a measure of the extent to which adult weekly drinkers felt motivated by them to reduce the amount of alcohol they drink. A secondary aim was to determine the top-ranked ads for drinkers overall compared with high-risk drinkers and other key demographic subgroups, providing a preliminary test of the merit of a 'common denominator' approach. A third aim was to identify the informational content, executional style and other message features associated with highly ranked ads.

\section{METHOD}

\section{Design and setting}

In an online study, Australian adult drinkers viewed and responded to three alcohol harm reduction television ads randomly selected from a pool of 83 ads. The study design minimised the possibility of order effects via random selection of ads from the pool and presenting them in a random order to each participant. The final rating obtained for each ad was aggregated across individuals and across orderings, and therefore controlled for order effects. Fieldwork was undertaken in OctoberNovember 2015.

\section{Participants}

The sample comprised 2174 18-64 year olds who reported consuming alcohol at least 1-2 days per week on average over the past 12 months ('weekly drinkers'). ${ }^{10}$ Participants were ineligible if they were pregnant or worked in health promotion, market research, advertising or the alcohol industry. Participants were recruited through an online panel that was accredited under the 
International Organization for Standardization's (ISO) standards for access panels in market, opinion and social research (AS ISO 26362). Quotas were applied to achieve approximately even numbers of men and women, and those aged 18-29 years (younger adults) and 30-64 years (older adults).

While others have shown through modelling that stable ad ratings can be achieved with as few as 23 individuals rating each ad, ${ }^{44}$ we set our target higher since random assignment of ads to participants meant some variability in the exact number of individuals rating each ad. We aimed for a sample size of 70 ratings per ad to facilitate comparisons of ad ratings within the key demographic subgroups of men/women (35 ratings per ad) and younger/older adults (35 ratings per ad).

\section{Procedure}

Panel members were invited to participate via email with a web link to the study. Potential participants first completed questions assessing qualifying criteria and quotas. Prior to viewing ads, eligible participants were informed that some ads may be from different countries and that when watching each ad they should focus on its main message and imagery, rather than production quality or cultural differences such as accents. Participants were then shown their first ad twice, and asked to complete a series of ad ratings. This process was repeated for the remaining two ads randomly assigned to the participant.

\section{Alcohol harm reduction ads}

A total of 83 ads were included, drawn from a recent content analysis of 110 English-language alcohol harm reduction ads produced from 2006 to $2014 .{ }^{45}$ The original 110 ads were identified as part of an exhaustive internet search of Google, video-sharing sites YouTube and Vimeo and relevant government and health agency websites. For the purposes of the current study, we excluded ads that targeted children or adolescents $(n=8)$ or governments $(n=3)$, advocated for policy reform $(n=6)$ or were $<30$ s or $>60$ s long $(n=10)$.

The large sample of ads allowed for variation in ad characteristics. Each ad was coded against 11 variables describing informational content, emotional tone, execution and country of origin. Inter-rater reliability exceeded acceptable levels for all variables with an average Krippendorff's $\alpha$ of 0.92 ; details of the coding procedure are reported elsewhere. ${ }^{45}$ Appendix A in the online supplementary material provides a summary of the characteristics and a synopsis of each ad.

\section{Measures}

\section{Motivation}

After viewing each ad, participants completed a set of questions assessing their cognitive and emotional responses. In the current study, we focussed on the primary outcome of motivation to reduce the amount of alcohol consumed. This was determined by asking participants to indicate on a five-point scale (1 'strongly disagree'-5 'strongly agree') the extent to which they 'felt motivated to reduce the amount of alcohol I drink' while watching the ad. Self-reported motivation to engage in behaviour change was part of the personalised perceived effectiveness scale validated as a predictor of subsequent behaviour change following exposure to tobacco control ads, ${ }^{42}$ and is consistent with recent recommendations that the potential effectiveness of behaviour change messages be assessed by asking participants to report how likely it is that they will be personally affected in the way intended by the message. ${ }^{43}$ There were moderate to strong positive correlations, ranging from 0.51 to 0.72 , between this overarching general drinking reduction motivation and other more specific motivations, namely being motivated to: limit my drinking so I don't get drunk; behave responsibly when I drink; look after my friends and family when they are drinking; talk to a friend or family member about their drinking; limit my drinking when around children and teenagers; never supply alcohol to teenagers and (among parents) talk to my children about alcohol. These seven items were developed specifically for the study, and were intended to cover the full spectrum of behavioural objectives targeted by these ads, as identified in our recent content analysis. ${ }^{45}$ The correlation results suggest that while different ads may seek to influence particular behaviours, if they are successful in doing so, they also elicit an overall motivation to reduce the amount of alcohol a person drinks. We therefore used this general reduced drinking motivational outcome as our primary ranking criterion; however, in a supplementary report, we present findings for all seven motivation items, to assist jurisdictions to select messages with the greatest potential to motivate adult drinkers to engage in a range of behaviours to reduce harm from alcohol. ${ }^{46}$

\section{Drinking behaviours and attitudes}

Baseline alcohol consumption was first assessed using the graduated quantity frequency measure, ${ }^{10}$ a measure of average pattern of consumption based on how often in the past 12 months (every day, 5-6 days a week, 34 days a week, 1-2 days a week, 2-3 days a month, about 1 day a month, less often or never) participants had each of the following number of standard drinks in a day $(20+, 11-19,7-10,5-6,3-4,1-2,<1$ or no alcohol in a day). A standard drink in Australia is classified as $10 \mathrm{~g}$ of alcohol, ${ }^{47}$ and to aid accurate responses participants were provided with a visual guide of the number of standard drinks in common serving sizes of different alcoholic beverages. Applying the Australian National Health and Medical Research Council's (NHMRC) 2009 guidelines for low-risk drinking, ${ }^{48}$ participants were classified as being at high risk of short-term harm if they reported having $>4$ drinks on any occasion at least once a month, and as being at high risk of long-term harm if they consumed $>2$ drinks per day on average. Participants were further classified into one of four 
categories: (1) low risk of harm in the short term and long term; (2) high risk of short-term harm but low risk of long-term harm; (3) low risk of short-term harm but high risk of long-term harm or (4) high risk of harm in the short term and long term. For comparative analyses, these categories were aggregated to compare those at low risk in the short term and long term (1; 'low-risk drinkers') with those at high risk in either or both the short term or long term (2, 3, 4; 'high-risk drinkers'). Consumption was also measured using the seven-day timeline follow-back method, ${ }^{48}$ to provide an estimate of recent consumption, whereby participants indicate how many alcoholic standard drinks they consumed each day of the past week, with each day and date labelled automatically in the online survey depending on the date of study completion.

Participants were asked one question about their perceived level of risk (adapted from ${ }^{49}$ ): How would you describe the amount of alcohol you currently drink? Response options included: (1) 'I definitely drink more than I should'; (2) 'I probably drink more than I should'; (3) 'The amount I drink is ok' and (4) 'I could drink more than I do'. Response options (1) and (2) were combined and classified as 'at risk'; responses (3) and (4) were combined and classified as 'low risk'. Two questions measured the importance of alcohol to the individual's self-identity (adapted from studies measuring the importance of tobacco smoking to selfidentity $^{50} 51$ ): 'drinking is part of who I am' and 'drinking is a part of my personality'. Responses were assessed using a five-point scale ( 1 'strongly disagree' -5 'strongly agree'), and were averaged to form a two-item measure of alcohol identity $(\alpha=0.904)$.

\section{Participant characteristics}

Respondents reported their sex, age, highest level of education completed (not tertiary vs tertiary), whether they were the parent/carer of any children and their postcode. Postcode was used to assign location (metropolitan vs rural) and area-based socioeconomic status (SES) ${ }^{52}$ After viewing each of their three randomly selected ads, participants reported if they had seen the ad before.

\section{Statistical analyses}

Data were analysed using Stata/SE 14.2 (StataCorp. Stata Statistical Software: Release 14.2. College Station, TX: StataCorp LP; 2016). Multivariable linear regression models provided predicted means on the outcome of 'motivated to reduce the amount of alcohol I drink' for each ad, and assessed the statistical significance of differences between each ad and (1) the highest and then (2) the lowest ranked ad. One set of models was conducted for the overall sample ( $\mathrm{N}=6522$ unique ad ratings). Additional models were conducted stratified by demographic subgroups to examine differences in participants' ad rankings by age group (younger adults $(\mathrm{n}=3513$ unique ad ratings $)$ and older adults $(\mathrm{n}=3009))$, sex (men $(\mathrm{n}=3123)$ and women $(\mathrm{n}=3999))$ and drinking risk status (low risk $(\mathrm{n}=3327)$ and high risk $(\mathrm{n}=3195)$ ). All models (overall sample and stratified models) employed data that were clustered by participant identification number to account for the same individual rating three ads using the cluster option in Stata, whereby robust SEs are used to allow for intragroup correlation. All models controlled for participant characteristics used for sample recruitment quotas and/or that were significantly associated with the outcome in bivariate models: NHMRC risk status (in four categories, as described above), perceived risk status, sex, tertiary education, parental status, age (continuous), familiarity with the ads, past 7 day alcohol consumption and alcohol identity.

We used Fisher's exact tests to compare the characteristics of ads that were ranked in the top $15 \%$ $(\mathrm{n}=12$ ads) with those ranked in the middle $70 \%$ $(n=59)$ and the bottom $15 \%(n=12)$ within the overall sample. Fifteen per cent ( $\mathrm{n}=12$ ads) was chosen as the cut-off for the sets of top-ranked/bottom-ranked ads, as this provided a balance between having a sufficient number of ads to give stable estimates of the characteristics within each group while also limiting the number of ads to be considered by campaign planners wishing to select one of the top performing for use in their own jurisdiction.

\section{RESULTS}

\section{Sample characteristics}

Around half of participants $(46 \%)$ were classified as high risk for short-term alcohol-related harm and 31\% were classified as high risk for long-term harm. When combined into the four-category variable, $51 \%$ were classified as low risk for short-term and long-term harm, $18 \%$ were at high risk of short-term harm but low risk of long-term harm, $3 \%$ were at low risk of short-term harm but high risk of long-term harm and $28 \%$ were at high risk of short-term and long-term harm (table 1). When further aggregated for comparative analysis, overall $49 \%$ were high-risk drinkers (at risk of short-term and/or long-term harm) and the remaining 51\% were low-risk drinkers. Risk proportions were similar to those calculated for adult weekly drinkers sourced from the 2013 National Drug Strategy Household Survey (NDSHS). ${ }^{10}$ The proportion of 18-29 year olds in the sample (54\%) was higher than in the NDSHS due to the use of age quotas during study recruitment. However, the sample was largely comparable with the NDSHS sample in terms of sex, residential location, SES, tertiary education and parental status (table 1).

\section{Ad rankings on 'motivation to reduce the amount} of alcohol I drink'

Overall, each ad was rated by between 58 and 102 participants, with an average of 79 ratings per ad. Table 2 
Table 1 Sample characteristics, compared with characteristics of weekly drinkers aged 18-64 in the Australian Institute of Health and Welfare's National Drug Strategy Household Survey (NDSHS)

\begin{tabular}{|c|c|c|}
\hline & $\begin{array}{l}\text { Study sample } \\
(n=2174) \\
\%\end{array}$ & $\begin{array}{l}\text { NDSHS } 2013 \\
(\mathrm{n}=8165) \\
\%\end{array}$ \\
\hline \multicolumn{3}{|l|}{ NHMRC risk status } \\
\hline Low risk of harm in the short term and long term & 51 & 47 \\
\hline High risk of short-term harm, low risk of long-term harm & 18 & 17 \\
\hline Low risk of short-term harm, high risk of long-term harm & 3 & 4 \\
\hline High risk of harm in the short term and long term & 28 & 33 \\
\hline \multicolumn{3}{|l|}{ Perceived risk status } \\
\hline Low risk & 59 & $\mathrm{n} / \mathrm{a}$ \\
\hline At risk & 41 & $\mathrm{n} / \mathrm{a}$ \\
\hline Sex (\% male) & 48 & 58 \\
\hline \multicolumn{3}{|l|}{ Age } \\
\hline $18-29$ years & 54 & 22 \\
\hline 30-64 years & 46 & 78 \\
\hline Location (\% metropolitan) & 68 & 70 \\
\hline \multicolumn{3}{|l|}{ Socioeconomic status ${ }^{*}$} \\
\hline Low $(0-40 \%)$ & 30 & 30 \\
\hline Middle (41-80\%) & 44 & 44 \\
\hline High $(81-100 \%)$ & 25 & 26 \\
\hline Completed tertiary education† (\% yes) & 70 & 72 \\
\hline \multirow[t]{2}{*}{ Parent/carer of child of any age $\ddagger$ (\% yes) } & 43 & 46 \\
\hline & M (SD) & M (SD) \\
\hline Age & $35.5(14.5)$ & $42.0(12.7)$ \\
\hline Past 7 day alcohol consumption (standard drinks) & $12.6(15.4)$ & $\mathrm{n} / \mathrm{a}$ \\
\hline Alcohol identity (5-point scale: 1 weak alcohol identity-5 strong alcohol identity) & $2.7(1.2)$ & $\mathrm{n} / \mathrm{a}$ \\
\hline \multicolumn{3}{|c|}{$\begin{array}{l}{ }^{*} \mathrm{n}=18 \text { missing in current study. } \\
\mathrm{n}=288 \text { missing in AlHW NDSHS. } \\
\mathrm{f}=631 \text { missing in AlHW NDSHS. } \\
\text { AlHW, Australian Institute of Health and Welfare; NDSHS, National Drug Strategy Household Survey; NHMRC, National Health and Medical } \\
\text { Research Council. }\end{array}$} \\
\hline
\end{tabular}

presents all 83 ads ranked in order of the predicted mean scores for the outcome 'motivated to reduce the amount of alcohol I drink'.

With a mean score of 3.77 , the highest ranked ad was Spread, developed and funded by the Western Australian state government as part of their Alcohol and cancer mass media campaign. Ads ranked in the second to seventh positions-What you can't see $(\mathrm{M}=3.62)$ from the same Western Australian campaign, Danny $(\mathrm{M}=3.57)$ from New Zealand's Not the drinking campaign, Male $(\mathrm{M}=3.51)$ from the UK's Damage you can't see campaign, Could happen to you $(\mathrm{M}=3.45)$ also from the Western Australian Alcohol and cancer campaign, Female $(\mathrm{M}=3.44)$ from the Damage you can't see campaign and Change4Life $(\mathrm{M}=3.44)$ from the UK-all performed comparably with Spread in that they did not score significantly differently on the motivation outcome. From the eighth-ranked ad onwards, adjusted mean scores were significantly lower than for Spread. With a mean score of 2.42, the lowest ranked ad was Add nothing from the Not beersies campaign from New Zealand. Ads ranked in positions 81 and 82Nails $(\mathrm{M}=2.64)$ and Piercings $(\mathrm{M}=2.69)$, both from Singapore's When to stop campaign-did not perform significantly better than Add nothing, whereas ads in position 80 and higher all scored significantly better than Add nothing (table 2).

\section{Ad rankings by demographic subgroup}

Across the 83 ads, the mean level of ad-attributed motivation to reduce drinking did not differ by sex (men $=3.14$, women $=3.17$ ) or risk level (low risk $=3.18$, high risk $=3.13$ ), but younger adults reported a higher mean level of ad-attributed motivation to reduce their drinking (3.21) than older adults (3.08), $t(164)=3.42, \mathrm{p}<0.001$.

We assessed the degree of consistency in ad rankings across subgroups in two ways. First, we examined which ads were in the top-ranked $15 \%$ within each subgroup and the extent to which these overlapped with the top-ranked $15 \%$ for the overall sample (table 3). Of the 12 ads that were top ranked in the overall sample, six were also top ranked among younger adults, nine were top ranked by older adults, seven were top ranked by men, eight were top ranked by women, ten were top ranked by low-risk drinkers and eight were top ranked by high-risk drinkers. More specifically, the ad ranked highest overall-Spread - was also ranked in the number one or two positions within each audience subgroup. Similarly, the second highest ranked ad overall-What 
Table 2 Rank and predicted mean score on the outcome of 'motivated to reduce the amount of alcohol I drink' for 83 alcohol harm reduction ads

\begin{tabular}{|c|c|c|c|c|}
\hline \multirow[b]{2}{*}{ Ad name; campaign [country] } & \multicolumn{4}{|c|}{ Total (6522 observations) } \\
\hline & (n) & & & Predicted mean \\
\hline Spread; Alcohol and cancer [Australia] & (66) & \multirow{12}{*}{$\begin{array}{l}\stackrel{\circ}{\circ} \\
\text { 응 } \\
\vdash\end{array}$} & 1 & 3.77 \\
\hline What you can't see [Australia] & (82) & & 2 & 3.62 \\
\hline Danny, Not the drinking [New Zealand] & (99) & & 3 & 3.57 \\
\hline Male; Damage you can't see [UK] & (94) & & 4 & 3.51 \\
\hline Could happen to you; Alcohol and cancer [Australia] & (64) & & 5 & 3.45 \\
\hline Female; Damage you can't see [UK] & (69) & & 6 & 3.44 \\
\hline Change4Life [UK] & (78) & & 7 & 3.44 \\
\hline Male units; Know your limits [UK] & (73) & & 8 & 3.43 \\
\hline Tolerance of drunken behaviour [Australia] & (87) & & 9 & 3.41 \\
\hline Lisa; Not the drinking [New Zealand] & (81) & & 10 & 3.39 \\
\hline Don't kid yourself [Australia] & (73) & & 11 & 3.39 \\
\hline Boy, Can't rewind your actions [Australia] & (70) & & 12 & 3.38 \\
\hline Female units; Know your limits [UK] & (88) & & 13 & 3.36 \\
\hline Here's to [Australia] & (77) & & 14 & 3.36 \\
\hline Boy, Don’t turn up drunk [Australia] & (90) & & 15 & 3.33 \\
\hline Kat, Ease up [New Zealand] & (73) & & 16 & 3.32 \\
\hline Youth and alcohol don't mix [Bermuda] & (86) & & 17 & 3.32 \\
\hline Know when to say when [Australia] & (79) & & 18 & 3.32 \\
\hline Binge girl; Know your limits [UK] & (84) & & 19 & 3.32 \\
\hline Uncle; Not the drinking [New Zealand] & (73) & & 20 & 3.31 \\
\hline Don't let alcohol abuse you [Ireland] & (99) & & 21 & 3.30 \\
\hline Do something about drunkenness [Australia] & (72) & & 22 & 3.29 \\
\hline Matt, Ease up; [New Zealand] & (74) & & 23 & 3.28 \\
\hline Rosie; Not the drinking [New Zealand] & (75) & & 24 & 3.28 \\
\hline Emily, Start talking [USA] & (85) & & 25 & 3.27 \\
\hline Another night wasted [UK] & (81) & & 26 & 3.27 \\
\hline Tumour [UK] & (68) & & 27 & 3.26 \\
\hline Party_Pub; Night out nightmare [Australia] & (80) & & 28 & 3.25 \\
\hline Say yeah, nah [New Zealand] & (76) & & 29 & 3.25 \\
\hline Influencer, Before it gets ugly [Australia] & (83) & & 30 & 3.21 \\
\hline Monsters [Finland] & (75) & & 31 & 3.20 \\
\hline Alley, Every drink counts [Australia] & (78) & & 32 & 3.20 \\
\hline Gary; Not the drinking [New Zealand] & (77) & & 33 & 3.19 \\
\hline Think twice [UK] & (80) & & 34 & 3.19 \\
\hline Male; Control your other you [USA] & (81) & & 35 & 3.19 \\
\hline Families and alcohol [UK] & (76) & & 36 & 3.18 \\
\hline Stain; Alcohol and cancer [Australia] & (80) & & 37 & 3.17 \\
\hline Brandon; Start talking [USA] & (71) & $\uparrow$ & 38 & 3.17 \\
\hline Munro; Not the drinking [New Zealand] & (74) & 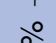 & 39 & 3.15 \\
\hline Binge boy; Know your limits [UK] & (75) & రి & 40 & 3.15 \\
\hline Think before you drink [Australia] & (85) & $\circ$ & 41 & 3.14 \\
\hline Superhero; Know your limits [UK] & (86) & $\stackrel{\circ}{\vdash}$ & 42 & 3.14 \\
\hline Receptionist, Champion moves [Australia] & (73) & $\stackrel{\circ}{\circ}$ & 43 & 3.13 \\
\hline Catwalk, Know your limits [UK] & (64) & 유 & 44 & 3.13 \\
\hline Boy, You, your child and alcohol [UK] & (83) & $\varepsilon$ & 45 & 3.11 \\
\hline Muzzle; Champion moves [Australia] & (102) & 吾 & 46 & 3.11 \\
\hline Too much booze, we all lose [Australia] & (85) & ๓ & 47 & 3.10 \\
\hline I see [Australia] & (83) & & 48 & 3.10 \\
\hline Don't be the one to miss out [UK] & (84) & & 49 & 3.09 \\
\hline Male; You always have a choice [Canada] & (79) & & 50 & 3.08 \\
\hline Snake-eye Stevie; No excuses [Australia] & (76) & & 51 & 3.08 \\
\hline Girl; Don't turn up drunk [Australia] & (89) & & 52 & 3.08 \\
\hline Girl; Can't rewind your actions [Australia] & (83) & & 53 & 3.07 \\
\hline Lasso; Champion moves [Australia] & (67) & & 54 & 3.06 \\
\hline
\end{tabular}




\begin{tabular}{|c|c|c|c|c|}
\hline \multirow[b]{2}{*}{ Ad name; campaign [country] } & \multicolumn{4}{|c|}{ Total (6522 observations) } \\
\hline & (n) & & & Predicted mean \\
\hline Sam; Ease up [New Zealand] & (77) & & 55 & 3.06 \\
\hline Bloody Mary, Cocktales [UK] & (76) & & 56 & 3.06 \\
\hline Feel the freshness; Not beersies [New Zealand] & (67) & & 57 & 3.06 \\
\hline Girl; You, your child and alcohol [UK] & (90) & & 58 & 3.06 \\
\hline Children and alcohol don't mix [UK] & $(78)$ & & 59 & 3.04 \\
\hline Cogs [Australia] & (82) & & 60 & 3.04 \\
\hline Female; You always have a choice [Canada] & (77) & & 61 & 3.03 \\
\hline Crash; Every drink counts [Australia] & (72) & & 62 & 3.03 \\
\hline Tequila slammer, Cocktales [UK] & (79) & & 63 & 3.03 \\
\hline Female; Control your other you [USA] & (58) & & 64 & 3.02 \\
\hline Underage drinking [Ireland] & (67) & & 65 & 3.02 \\
\hline Male youth; Control your other you [USA] & (76) & & 66 & 3.00 \\
\hline Don't drink and drown [Australia] & (77) & & 67 & 2.99 \\
\hline Don't leave your brain at home [UK] & (70) & & 68 & 2.99 \\
\hline Aggressor, Before it gets ugly [Australia] & (79) & & 69 & 2.98 \\
\hline Protect your growing children [Netherlands] & (94) & & 70 & 2.98 \\
\hline Are you a binge drinker? [USA] & $(78)$ & & 71 & 2.97 \\
\hline Nightclub; Drink too much [Australia] & (89) & & 72 & 2.95 \\
\hline Dad; Talk. They hear you [USA] & (58) & & 73 & 2.95 \\
\hline Marathon Millie; No excuses [Australia] & (81) & & 74 & 2.94 \\
\hline Stupid ideas [USA] & (63) & & 75 & 2.93 \\
\hline Mom; Talk. They hear you [USA] & (68) & & 76 & 2.93 \\
\hline The secret, Not beersies [New Zealand] & (86) & & 77 & 2.92 \\
\hline A coward's punch can kill [Australia] & (86) & & 78 & 2.88 \\
\hline Alcohol destroys [Macedonia] & (80) & $\alpha^{\circ}$ & 79 & 2.86 \\
\hline Angie [Australia] & (91) & $\stackrel{0}{2}$ & 80 & 2.86 \\
\hline Piercings; When to stop [Singapore] & (84) & $\varepsilon$ & 81 & 2.69 \\
\hline Nails; When to stop [Singapore] & (83) & 온 & 82 & 2.64 \\
\hline Add nothing; Not beersies [New Zealand] & (71) & ஜ̊ & 83 & 2.42 \\
\hline
\end{tabular}

you can't see-was ranked in second, third or fourth place in all subgroups except the low-risk drinkers (for whom it ranked 10th). The third highest ranked ad overall-Danny-was ranked in the top two or three in all subgroups except men (among whom it ranked 9th). We also examined the Spearman rank order correlation between the rankings of all 83 ads across the age, sex and risky drinking subgroups. The rank order of the 83 ads between the younger and older adults was significantly correlated, $r_{s}(81)=0.42, \mathrm{p}<0.001$. Similarly, the rank order of the 83 ads between men and women was significantly correlated, $r_{s}(81)=0.45, \mathrm{p}<0.001$, and so was the rank order of the 83 ads between low-risk and highrisk drinkers, $r_{s}(81)=0.46, \mathrm{p}<0.001$.

\section{Characteristics of highly ranked ads}

We compared the characteristics of the top-ranked $15 \%$ of ads in the overall sample with the characteristics of the middle-ranked $70 \%$ and bottom-ranked $15 \%$ of ads (table 4). Regarding the key communication intent of the ad, the distribution of ads containing a "why change behaviour' intent was significantly different across the three groups, with all of the top-ranked ads carrying a 'why' message but only half of the bottom-ranked ads doing so. In addition, $58 \%$ of the top-ranked ads featured information on the long-term harms of alcohol consumption, compared with $7 \%$ of middle-ranked ads and none of the bottom-ranked ads. (Not shown in table 4, seven of the top-ranked ads featured information on long-term harms. Of these seven ads, six mentioned cancer, four mentioned stroke, two mentioned heart disease, two mentioned high blood pressure, one mentioned liver disease and one ad mentioned other nonspecific 'serious health problems'. In addition, of the four middle-ranked ads that featured long-term harms, cancer was mentioned in three and other non-specific 'serious health problems' were mentioned in one). A higher proportion of all top-ranked ads presented low-risk drinking guidelines (58\%) compared with the middle-ranked (5\%) and bottom-ranked ads (0\%).

The distribution of ads differed by emotional tone, with $50 \%$ of bottom-ranked ads having a positive tone compared with none of the top-ranked ads. Conversely, $92 \%$ of top-ranked ads had a negative tone compared 


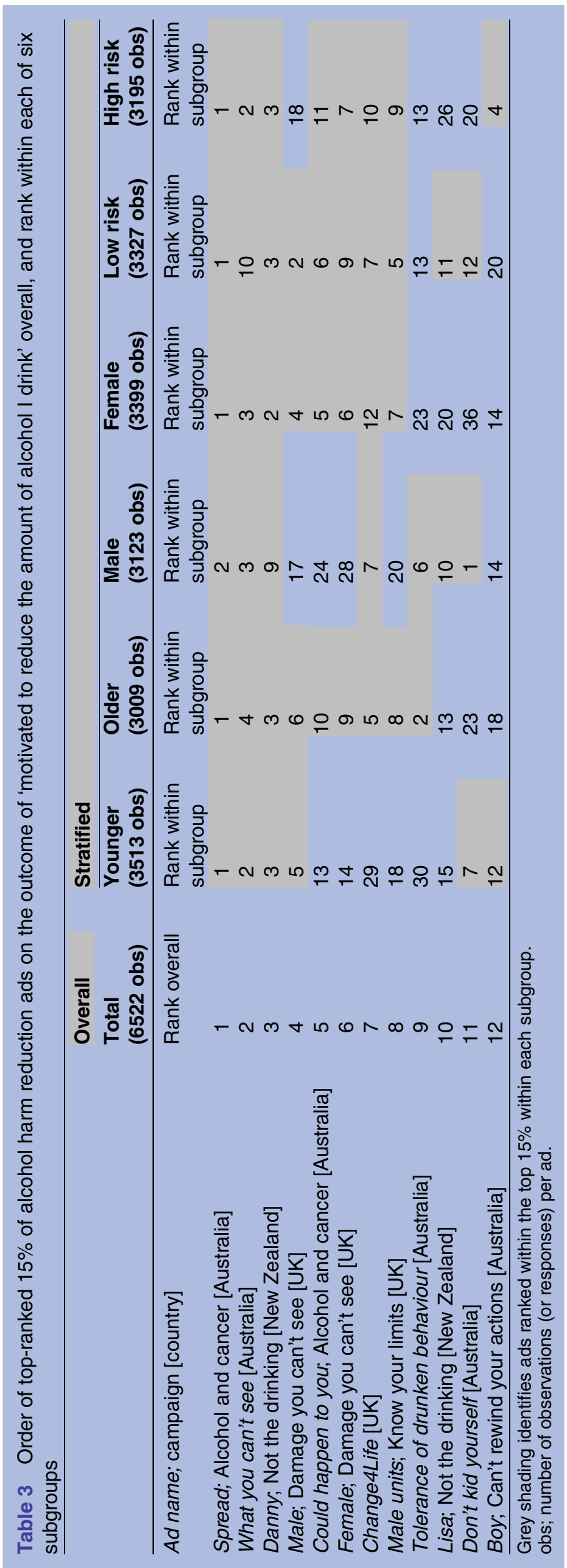

with $50 \%$ of bottom-ranked ads, although this difference did not reach statistical significance $(p=.085)$. In terms of execution, top-ranked ads were less likely to feature a dramatisation communication style $(67 \%$ compared with $100 \%$ of bottom-ranked ads). While top-ranked ads appeared more likely than others to use simulation/ animation $(25 \%)$, this difference was not statistically significant.

While top-ranked ads did not differ in their use of graphic imagery, they were more likely than bottomranked ads to contain explicit portrayals of drinking (58\% vs $8 \%$, respectively) and were less likely to contain no portrayal of drinking than middle-ranked or bottomranked ads ( $0 \%$ vs $25 \%$ and $75 \%$, respectively). Finally, a significantly higher proportion of top-ranked ads targeted a general adult audience (83\%), whereas middle-ranked (46\%) and bottom-ranked ads (58\%) were more likely to specifically target young adults (table 4).

\section{DISCUSSION}

The first aim of the study was to rank a large pool of alcohol harm reduction ads according to the extent to which adult weekly drinkers felt motivated by them to reduce their own alcohol consumption. Although motivation responses for all ads were within the middle range of the five-point scale (2.42-3.77), we identified several specific ads that topped the list and also identified the top-ranked $15 \%$ of ads and the message characteristics that significantly distinguished these from lower ranked ads. Campaign messages that drinkers found most motivating were those that directly communicated why change was advisable or necessary, rather than how to achieve such change, a finding consistent with that from tobacco control ${ }^{14}{ }^{30}$ and obesity prevention. ${ }^{53}$ Top-ranked ads were also more likely to address longterm harms, conditions that are likely to reflect where most alcohol educational deficits exist. ${ }^{54}$ Emotional tone of the ads also differed across the three ranked categories, with ads featuring a positive tone more likely to be in the bottom-ranked $15 \%$ and top-ranked ads tending to be more likely to have a negative emotional tone (albeit not reaching statistical significance). This pattern of findings is broadly consistent with a recent small study of drinkers in the UK which found negative emotion mediated the effects of alcohol harm reduction ads on lower urges to drink. ${ }^{34}$ Inclusion of low-risk guidelines or recommendations was also more likely in top-ranked ads, suggesting this message element may have potency. Furthermore, although rankings varied somewhat, there was substantial overlap in the top-ranked ads across key demographic groups of younger and older adults, men and women and highrisk and low-risk drinkers, as was also reflected in the high correlations in rankings between subgroups. In particular, it was of interest to note how well the long-term harm ads performed with younger people, who might 
Table 4 Characteristics of the top 15\%, middle $70 \%$ and bottom $15 \%$ of alcohol harm reduction ads, according to motivation to reduce drinking

\begin{tabular}{|c|c|c|c|c|c|}
\hline & $\begin{array}{l}\text { Total } \\
(\mathrm{N}=83) \\
\%\end{array}$ & $\begin{array}{l}\text { Top 15\% } \\
(n=12) \\
\%\end{array}$ & $\begin{array}{l}\text { Middle } 70 \% \\
(n=59) \\
\%\end{array}$ & $\begin{array}{l}\text { Bottom } 15 \% \\
(n=12) \\
\%\end{array}$ & $\begin{array}{l}\text { Fisher's exact } \\
\text { test } p \text { Value }\end{array}$ \\
\hline \multicolumn{6}{|l|}{ Informational content } \\
\hline Communication intent & & & & & 0.005 \\
\hline Why change behaviour & 83 & 100 & 86 & 50 & 0.005 \\
\hline How to change behaviour & 17 & 0 & 14 & 50 & 0.005 \\
\hline Dominant communication topic & & & & & $<0.001$ \\
\hline Short-term harms & 54 & 33 & 61 & 42 & 0.151 \\
\hline Long-term harms & 13 & 58 & 7 & 0 & $<0.001$ \\
\hline Underage harms/role modelling & 16 & 8 & 19 & 8 & 0.708 \\
\hline How to change behaviour & 17 & 0 & 14 & 50 & 0.005 \\
\hline Drinking guidelines (\% yes) & 12 & 58 & 5 & 0 & $<0.001$ \\
\hline Emotional tone & & & & & 0.017 \\
\hline Negative & 73 & 92 & 75 & 50 & 0.085 \\
\hline Positive & 14 & 0 & 10 & 50 & 0.002 \\
\hline Negative and positive & 11 & 8 & 14 & 0 & 0.633 \\
\hline Neutral & 1 & 0 & 2 & 0 & 1.000 \\
\hline \multicolumn{6}{|l|}{ Execution } \\
\hline Style & & & & & 0.026 \\
\hline Dramatisation & 89 & 67 & 92 & 100 & 0.033 \\
\hline Simulation/animation & 10 & 25 & 8 & 0 & 0.109 \\
\hline Factual & 1 & 8 & 0 & 0 & 0.289 \\
\hline Graphic imagery (\% yes) & 20 & 17 & 24 & 8 & 0.583 \\
\hline Portrayal of drinking & & & & & 0.001 \\
\hline No portrayal & 29 & 0 & 25 & 75 & $<0.001$ \\
\hline Implicit portrayal only & 31 & 42 & 32 & 17 & 0.430 \\
\hline Explicit portrayal & 40 & 58 & 42 & 8 & 0.030 \\
\hline Target audience & & & & & 0.010 \\
\hline Young adults ( $18-30$ years) & 42 & 8 & 46 & 58 & 0.021 \\
\hline General adult audience & 39 & 83 & 34 & 17 & 0.001 \\
\hline Parents & 19 & 8 & 20 & 25 & 0.566 \\
\hline Gender specific message (\% yes) & 10 & 25 & 5 & 17 & 0.053 \\
\hline Subject of depicted harms/consequences of drinking & & & & & 0.271 \\
\hline Self (the drinker) & 49 & 67 & 42 & 67 & 0.141 \\
\hline Others & 27 & 8 & 31 & 25 & 0.362 \\
\hline Self and others & 24 & 25 & 27 & 8 & 0.507 \\
\hline Country of origin & & & & & 0.156 \\
\hline Australia & 37 & 50 & 36 & 33 & 0.683 \\
\hline UK & 24 & 33 & 27 & 0 & 0.077 \\
\hline New Zealand & 16 & 17 & 15 & 17 & 1.000 \\
\hline USA & 11 & 0 & 10 & 25 & 0.149 \\
\hline Other† & 12 & 0 & 12 & 25 & 0.224 \\
\hline
\end{tabular}

have been expected to self-exempt from these more distal harms.

To the best of our knowledge, this is the first published study to identify and comparatively evaluate a large pool of alcohol harm reduction ads from many different countries using a standard criterion outcome measure with a large sample of drinkers. As ads were only rated by Australian drinkers, it could be assumed that ads produced in Australia would have been rated more highly than others. However, we found that the top-ranked $15 \%$ of ads was comprised of ads from Australia (six ads), the UK (four ads) and New Zealand (two ads), and we also found no significant differences in the distribution of ads across ranking categories by country of origin. By controlling for familiarity with the ads in our analyses, we further minimised the potential effect of country of production on responses to the ads. A study strength was that all ads were presented in a 
standard way, achieving consistent exposure. On the other hand, forced exposure may not reflect how viewers might respond in a natural media viewing situation where exposure occurs repeatedly over a longer duration. Another issue is that online non-probability panels do not provide a random population sample, and so we do not suggest our parameter estimates represent the national population statistically. However, online panels are typically used in the advertising industry to predict consumer responses to advertising, and the patterns of ad-elicited motivation observed in this large and varied sample are likely to reflect those in the population, particularly given the similarities between our sample's demographic and alcohol consumption characteristics with those of the benchmark national survey.

Another limitation was that our outcome measure was felt motivation to reduce drinking rather than drinking behaviour change. In their description of the 'Big Five Principles of Behaviour Change', Hill and Dixon (2010) describe motivation as being a necessary condition for volitional behaviour, but they note that it is often insufficient on its own. ${ }^{55}$ Mass media campaigns (and other behaviour change programmes) can also address the other key principles of behaviour change, by modelling the desired behaviour (as demonstrated in the how-to-change behaviour ads in our sample), building capacity for change (by advocating for policy change), enabling people to remember the recommended behaviours (by ensuring sufficient campaign exposure and repetition at regular intervals) and providing reinforcement for the desired behaviour (by demonstrating the negative consequences of failing to reduce alcohol consumption). ${ }^{55}$ Further research could investigate the extent to which the effectiveness of alcohol harm reduction ads may be enhanced by addressing these other determinants of behaviour change.

Collectively, this information may guide countries to develop campaign messages with the key features identified here, or to select any of the existing top-ranked ads with most potential to motivate change in adult drinking behaviour for broadcast in their own jurisdictions. Given the substantial upfront costs and resources involved in developing mass media campaigns, recycling existing campaign materials can help to ensure that scarce campaign resources can be directed towards achieving sufficient population exposure. ${ }^{56}{ }^{57}$ It is notable that the two highest ranked ads in this study_-Spread and What you can't see-predominantly consisted of animated imagery of the internal harms caused by alcohol (which are applicable to all people), rather than footage of models or settings that could be more culturally specific. These two ads are particularly suitable for low-cost adaptation for use in countries other than Australia given that the major adaptation required would be to revoice the ads and translate the final tagline. Recent tobacco control research has demonstrated the viability of adapting campaign messages shown to be effective in one setting for use in other jurisdictions. ${ }^{57}$ Studies comparing responses from smokers in 10 different countries found high levels of consistency in responses to different tobacco control ads across countries and demographic subgroups, particularly when these ads used graphic images to depict the physical effects of smoking in a direct and evocative manner. ${ }^{28}{ }^{29}$ We therefore recommend that the current findings be used by jurisdictions to identify those ads that, following local pretesting and any necessary adaptations for language and taglines, may help to motivate reduced alcohol consumption within their own adult populations.

In addition, our finding of consistent ad rankings across audience subgroups suggests that a 'common denominator approach' could have merit, thereby making scant resources go further. ${ }^{36}$ That is, by carefully selecting ads that appeared in the top-ranked category for all or most of the audience subgroups, countries could use a single campaign approach to motivate key demographic groups to reduce their drinking, while also resonating with the wider population to stimulate a broader cultural change process. However, we note that it is possible that the age groups compared in this study (18-29 year olds vs 30-64 year olds) were too broad to adequately capture variation in the range of responses to alcohol harm reduction ads across the age spectrum. Although all of our predicted mean scores on the motivation outcome were adjusted for age (including in the age-stratified models), future research may benefit from a more fine-grained segmentation when considering the effects of age in determining responses to alcohol harm reduction campaigns.

The promising performance of ads that carried a guideline message suggests that more widespread and systematic promotion of drinking guidelines accompanied by good reasons to limit consumption could serve to provide a new anchoring point for decisions about consumption $^{58}$ and shift public attitudes about alcohol. ${ }^{59}$ While there has been debate as to whether disseminating guidelines could confuse or backfire ${ }^{60}$ or even be relevant when many drinkers rely so much on their own sensed experience of how much they can drink ${ }^{61}$ some suggest that there is a moral imperative to inform consumers ${ }^{62}$ and recent empirical observations provide reasons for optimism regarding their potential effectiveness. ${ }^{59} 63$

This study has identified specific campaign messages that offer the most potential to increase motivation to reduce alcohol consumption in the broader population, as well as in key demographic and high-risk drinker subgroups. This information makes an important contribution to the limited evidence base on the potential for mass media campaigns to reduce alcohol-related harm. Although we noted earlier that perceived effectiveness measures-of which the motivation outcome used here is one-predict behaviour change for tobacco control ads, ${ }^{41}{ }^{42}$ further studies should examine the predictive validity of this and other perceived effectiveness 
outcomes for subsequent reduced drinking behaviour. Further research is also necessary to validate our assumption that the ads that performed most strongly among Australian drinkers would similarly impact drinkers in other jurisdictions. It would also be of interest to examine if certain long-term harms are more motivating than others, given six out of seven of the long-term harm ads in the top-ranked $15 \%$ of ads specifically mentioned cancer. Overall, our findings suggest there may be promise in resourcing alcohol harm reduction campaigns that educate audiences about why they may need to change their drinking by providing information about the long-term harms of risky alcohol use and communicating guidelines for low-risk drinking.

Contributors MAW, EB and KD designed the study, with input from all other authors. KD managed data collection. KD and EB analysed the data and interpreted the findings, with input from all other authors. MAW, EB and KD drafted the manuscript, with critical feedback from all other authors. All authors approved the final manuscript.

Funding This work was supported by Australian National Health and Medical Research Council project grant number GNT1070689.

Competing interests None declared.

Ethics approval Ethical approval to conduct the study was obtained from Cancer Council Victoria's Institutional Research Review Committee.

Provenance and peer review Not commissioned; externally peer reviewed.

Data sharing statement No data are available for sharing as data analysis has only just begun.

Open Access This is an Open Access article distributed in accordance with the Creative Commons Attribution Non Commercial (CC BY-NC 4.0) license, which permits others to distribute, remix, adapt, build upon this work noncommercially, and license their derivative works on different terms, provided the original work is properly cited and the use is non-commercial. See: http:// creativecommons.org/licenses/by-nc/4.0/

\section{REFERENCES}

1. Lim SS, Vos T, Flaxman AD, et al. A comparative risk assessment of burden of disease and injury attributable to 67 risk factors and risk factor clusters in 21 regions, 1990-2010: a systematic analysis for the Global Burden of Disease Study 2010. Lancet 2012;380:2224-60.

2. World Health Organization. Global status report on alcohol and health. Geneva, Switzerland: World Health Organization, 2014

3. Thomson LM, Vandenberg B, Fitzgerald JL. An exploratory study of drinkers views of health information and warning labels on alcohol containers. Drug Alcohol Rev 2012;31:240-7.

4. Buykx P, Li J, Gavens L, et al. An investigation of public knowledge of link between alcohol and cancer. University of Sheffield and Cancer Research UK, 2015. http://www.cancerresearchuk.org/sites/ default/files/an_investigation_of_public_knowledge_of_the_link between_alcohol_and_cancer_buykx_et_al.pdf (accessed 31 Aug 2016).

5. Bowden JA, Delfabbro P, Room R, et al. Alcohol consumption and NHMRC guidelines: has the message got out, are people conforming and are they aware that alcohol causes cancer?. Aust $N$ Z J Public Health 2014;38:66-72.

6. Ryan AM, Cushen S, Schellekens $\mathrm{H}$, et al. Poor awareness of risk factors for cancer in lrish adults: results of a large survey and review of the literature. Oncologist 2015;20:372-8.

7. Buykx P, Li J, Gavens L, et al. Public awareness of the link between alcohol and cancer in England in 2015: a population-based survey. Stockholm, Sweden: Kettil Bruun Society 42nd Symposium, 2016.

8. Merten JW, Parker A, Williams A, et al. Cancer risk factor knowledge among young adults. J Cancer Educ 2016 [Epub ahead of print].
9. Foundation for alcohol research and education. Alcohol annual poll: attitudes and behaviours. Canberra, ACT: foundation for alcohol research and education, 2014. http://fare.org.au/2014/03/ annual-alcohol-poll-2014/ (accessed 31 Aug 2016).

10. Australian Institute of Health and Welfare. National Drug Strategy Household Survey Detailed Report 2013. Canberra, Australia: Australian Institute of Health and Welfare, 2014. Drug Statistics Series No. 28. Cat. No. PHE 183. http://www.aihw.gov.au/WorkArea/ DownloadAsset.aspx?id=60129549848 (accessed 31 Aug 2016).

11. de Visser RO, Birch JD. My cup runneth over: young people's lack of knowledge of low-risk drinking guidelines. Drug Alcohol Rev 2012;31:206-12.

12. Buykx P, Gilligan C, Ward B, et al. Public support for alcohol policies associated with knowledge of cancer risk. Int J Drug Policy 2015;26:371-9.

13. Wakefield M, Loken B, Hornik R. Use of mass media campaigns to change health behaviour. Lancet 2010;376:1261-71.

14. Durkin S, Brennan E, Wakefield M. Mass media campaigns to promote smoking cessation among adults: an integrative review. Tob Control 2012;21:127-38.

15. US Department of Health and Human Services. Preventing tobacco use among youth and young adults: a report of the Surgeon General. Atlanta, GA: US Department of Health and Human Services, Public Health Service, Office of the Surgeon General, Rockville, MD. 2012. http://www.cdc.gov/tobacco/data_statistics/sgr/ 2012/index.htm (accessed 31 Aug 2016).

16. Elder RW, Shults RA, Sleet DA, et al. Effectiveness of mass media campaigns for reducing drinking and driving and alcohol-involved crashes: a systematic review. Am J Prev Med 2004;27:57-65.

17. Babor T, Caetano R, Casswell S, et al. Alcohol: no ordinary commodity. 2nd edn. New York, NY: Oxford University Press, 2010.

18. Martineau F, Tyner E, Lorenc T, et al. Population-level interventions to reduce alcohol-related harm: an overview of systematic reviews. Prev Med 2013;57:278-96.

19. National preventative health taskforce. Australia: the healthiest country by 2020 . Technical report 3 . Preventing alcohol-related harm in Australia: a window of opportunity. Canberra, ACT: Commonwealth of Australia, 2009. http://www.health.gov.au/internet/preventative health/publishing.nsf/Content/tech-alcohol-toc (accessed 31 Aug 2016).

20. Howard S, Gordon R, Jones S. Australian alcohol policy 20012013 and implications for public health. BMC Public Health 2014;14:848.

21. Wakefield MA, Durkin S, Spittal MJ, et al. Impact of tobacco control policies and mass media campaigns on monthly adult smoking prevalence. Am J Public Health 2008;98:1443-50.

22. White V, Durkin S, Coomber K, et al. What is the role of tobacco control advertising intensity and duration in reducing adolescent smoking prevalence? Findings from 16 years of tobacco control mass media advertising in Australia. Tob Control 2015;24:198-204.

23. Emery S, Wakefield MA, Terry-McElrath $\mathrm{Y}$, et al. Televised state-sponsored antitobacco advertising and youth smoking beliefs and behavior in the United States, 1999-2000. Arch Pediatr Adolesc Med 2005;159:639-45.

24. Malone RE, Grundy Q, Bero LA. Tobacco industry denormalisation as a tobacco control intervention: a review. Tob Control 2012;21:162-70.

25. Livingood WC Jr, Allegrante JP, Green LW. Culture change from tobacco accommodation to intolerance: time to connect the dots. Health Educ Behav 2016:43:133-8.

26. Alamar B, Glantz SA. Effect of increased social unacceptability of cigarette smoking on reduction in cigarette consumption. $A m$ J Public Health 2006;96:1359-63.

27. National Cancer Institute. The role of the media in promoting and reducing tobacco use. Tobacco control monograph no 19. Bethesda, MD: US Department of Health and Human Services, National Institutes of Health, National Cancer Institute, 2008. NIH Pub No 07-6242. http://cancercontrol.cancer.gov/tcrb/monographs/19/index. html (accessed 31 Aug 2016).

28. Durkin S, Bayly M, Cotter T, et al. Potential effectiveness of anti-smoking advertisement types in ten low and middle income countries: do demographics, smoking characteristics and cultural differences matter?. Soc Sci Med 2013;98:204-13.

29. Wakefield M, Bayly M, Durkin S, et al. Smokers' responses to television advertisements about the serious harms of tobacco use: pre-testing results from 10 low- to middle-income countries. Tob Control 2013;22:24-31.

30. Davis KC, Nonnemaker JM, Farrelly MC, et al. Exploring differences in smokers' perceptions of the effectiveness of cessation media messages. Tob Control 2011;20:26-33. 
31. McAfee T, Davis KC, Alexander RL, et al. Effect of the first federally funded US antismoking national media campaign. Lancet 2013;382:2003-11.

32. Nonnemaker JM, Allen JA, Davis KC, et al. The influence of antismoking television advertisements on cessation by race/ ethnicity, socioeconomic status, and mental health status. PLOS ONE 2014:9:e102943.

33. Dixon HG, Pratt IS, Scully ML, et al. Using a mass media campaign to raise women's awareness of the link between alcohol and cancer: cross-sectional pre-intervention and post-intervention evaluation surveys. BMJ Open 2015;5:e006511.

34. Stautz K, Marteau TM. Viewing alcohol warning advertising reduces urges to drink in young adults: an online experiment. BMC Public Health 2016;16:530.

35. Jones SC. Social marketing's response to the alcohol problem: who's conducting the orchestra? In: Hastings G, Angus K, Bryant C, eds. The SAGE Handbook of Social Marketing, 2011:253-71.

36. Hornik RC, Ramirez AS. Racial/ethnic disparities and segmentation in communication campaigns. Am Behav Sci 2006;49:868-84.

37. Hornik RC, Yanovitzky I. Using theory to design evaluations of communication campaigns: the case of the national youth anti-drug media campaign. Commun Theory 2003;13:204-24.

38. Brennan E, Gibson LA, Kybert-Momjian A, et al. Promising themes for antismoking campaigns targeting youth and young adults. Tob Regul Sci 2017;3:29-46.

39. Davis KC, Nonnemaker J, Duke J, et al. Perceived effectiveness of cessation advertisements: the importance of audience reactions and practical implications for media campaign planning. Health Commun 2013;28:461-72.

40. Bigsby E, Cappella JN, Seitz HH. Efficiently and effectively evaluating public service announcements: additional evidence for the utility of perceived effectiveness. Commun Monogr 2013;80:1-23.

41. Davis KC, Duke J, Shafer P, et al. Perceived effectiveness of antismoking ads and association with quit attempts among smokers: evidence from the tips from former smokers campaign. Health Commun 2016:1-8 [Epub ahead of print].

42. Brennan E, Durkin SJ, Wakefield MA, et al. Assessing the effectiveness of antismoking television advertisements: do audience ratings of perceived effectiveness predict changes in quitting intentions and smoking behaviours? Tob Control 2014;23:412-18.

43. Yzer M, LoRusso S, Nagler RH. On the conceptual ambiguity surrounding perceived message effectiveness. Health Commun 2015;30:125-34.

44. Kim M, Cappella JN. Efficient versus accurate testing: choosing an optimal sample size to evaluate message characteristics. 64th Annual International Communication Association Conference; 22-26 May. Seattle, WA, 2014.

45. Dunstone K, Brennan E, Slater MD, Dixon HG, Durkin SJ, Pettigrew S Wakefield MA, et al. Alcohol harm reduction advertisements: a content analysis of topic, objective, emotional tone, execution and target audience. BMC Public Health. In press.

46. Dunstone K, Brennan E, Durkin S, et al. Comparing alcohol harm reduction advertisements on their ability to motivate behaviour change. CBRC research paper series no 48. Melbourne, Australia: Centre for Behavioural Research in Cancer, Cancer Council Victoria, 2017. http://www.cancervic.org.au/research/behavioural/researchpapers/abstracts alcohol-harm-reduction-advertisement.html
47. Australian government department of health. The Australian standard drink. 2016 (updated 7 May 2012; cited 9 December 2016). http://www.alcohol.gov.au/internet/alcohol/publishing.nsf/ content/standard

48. National Health and Medical Research Council. Australian guidelines to reduce health risks from drinking alcohol. Canberra, ACT: National Health and Medical Research Council, Commonwealth of Australia, 2009. https://www.nhmrc.gov.au/guidelines-publications/ ds10 (accessed 31 Aug 2016).

49. Sobell LC, Sobell MB. Alcohol consumption measures. In: Allen JP, ed. Assessing alcohol problems: a guide for clinicians and researchers. Columbus, OH: DIANE, 1995:75-99.

50. TNS Social Research. Alcohol and health campaign evaluation 2014. Report for Drug \& Alcohol Office, Government of Western Australia, 2014

51. Falomir JM, Invernizzi F. The role of social influence and smoker identity in resistance to smoking cessation. Swiss J Psychol 1999;58:73.

52. Shadel WG, Mermelstein R. Individual differences in self-concept among smokers attempting to quit: validation and predictive utility of measures of the smoker self-concept and abstainer self-concept. Ann Behav Med 1996;18:151-6.

53. Australian Bureau of Statistics. Australian demographic statistics2011 census edition: final. Canberra, Australia: Australian Bureau of Statistics, 2012. Cat. No. 3101.0.

54. Dixon D, Scully M, Durkin S, et al. Finding the keys to successful adult-targeted advertisements on obesity prevention: an experimental audience testing study. BMC Public Health 2015;15:804.

55. Pettigrew S, Jongenelis M, Pratt IS, et al. Australian drinkers'perceptions of alcohol-related risk by consumption status. Addict Res Theory 2016;24:507-13.

56. Hill D, Dixon H. Achieving behavioural changes in individuals and populations. In: Elwood M, Sutcliffe S, eds. Cancer control. Don Mills, Ontario, Canada: Oxford University Press, 2010:43-61.

57. Cotter T, Perez D, Dunlop S, et al. The case for recycling and adapting anti-tobacco mass media campaigns. Tob Control 2010;19:514-17.

58. Mullin S, Prasad V, Kaur J, et al. Increasing evidence for the efficacy of tobacco control mass media communication programming in lowand middle-income countries. J Health Commun 2011;16(Suppl 2):49-58.

59. Tversky A, Kahneman D. Judgment under uncertainty: heuristics and biases. Science 1974;185:1124-31.

60. Marteau TM. Will the UK's new alcohol guidelines change hearts, minds-and livers?. BMJ 2016;352:i704.

61. Casswell S. Why have guidelines at all? A critical perspective. Drug Alcohol Rev 2012;31:151-2.

62. Lovatt M, Eadie D, Meier PS, et al. Lay epidemiology and the interpretation of low risk drinking guidelines by adults in the United Kingdom. Addiction 2015;110:1912-19.

63. Heather N. Drinking guidelines are essential in combating alcohol-related harm: comments on the new Australian and Canadian guidelines. Drug Alcohol Rev 2012;31: 153-5.

64. Livingston M. Perceptions of low-risk drinking levels among Australians during a period of change in the official drinking guidelines. Drug Alcohol Rev 2012;31:224-30. 